\title{
INFORMACIÓN POLÍTICA Y REDES SOCIALES EN ESTADOS UNIDOS: de Obama a Trump
}

\author{
Rafael Barberá González* \\ Ubaldo Cuesta Cambra*
}

RESUMEN

\begin{abstract}
En el campo de la información política asistimos a una hibridación de medios que explica el nuevo consumo de noticias. En los últimos años, el líder más relevante en hacer un uso político/ electoral de las redes sociales fue Barack Obama. Diseñó una estrategia online que, entre otros factores, le aupó a la presidencia de Estados Unidos. En 2016, Donald Trump detectó el target al que dirigirse, les escuchó y estableció una campaña online para hacerles llegar mensajes de información política. El propósito de este artículo es analizar y monitorizar las redes de Obama y Trump, durante el periodo crítico electoral con el fin último de colaborar con los nuevos modelos de comunicación política para verificar si los resultados, como señala CHADWICK (20I3), confirman que los nuevos medios se interrelacionan con los viejos.
\end{abstract}

Palabras clave: Estados Unidos. Comunicación. Elecciones. Medios de información.

\begin{abstract}
* Doutor em Direito pela Universidade Complutense de Madrid, Espanha. Professor Associado do Departamento de Teorías e Análise da Comunicação da Universidade Complutense de Madrid, Espanha. Diretor dos Mestrados em Periodismo Audiovisual e em Produção e Realização Audiovisual na Universidade Francisco de Vitória, Espanha.

E-mail: rbarbera@ucm.es.

* Doutor em Psicologia e Estudos de Mídias e Comunicação de Massas pela Universidade Complutense de Madri, Espanha. Catedrático de Comunicação, Audiovisual e Publicidade da Universidade Complutense de Madri, Espanha. Diretor do Departamento de Teoria e Análises da Comunicação da Universidade Complutense de Madri, Espanha. E-mail: ucuestac@ucm.es.
\end{abstract}

\section{INTRODUCCIÓN}

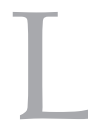
os diferentes sectores que componen la sociedad han comprobado que es necesario estar presentes en la red para aumentar su proyección.

Los actores políticos, como consecuencia de lo anterior, son conscientes de que sus mensajes y estrategias necesitan de las redes sociales si quieren llegar a públicos nuevos y más amplios.

La información política, en la actualidad, se genera y distribuye también a través de los 'social media'. De hecho han nacido nuevos medios que se difunden solo a través de la red. Dan soporte a las opiniones de los políticos. Y éstos, a su vez, las expresan en herramientas como Twitter o Facebook, algo que hace no muchos años era impensable.
En la información que se brinda en una campaña electoral Internet ofrece mayor capacidad de hacerla llegar. Vonderschmitt (2012) considera que "esto no solo le ha dado a la gente más voz en la campaña sino que también puede aplicarse cuando los candidatos elegidos se instalan en sus despachos y escuchan las relaciones que han construido durante la campaña. Esto crea un mejor diálogo y, en última instancia, una mejor democracia".

Estamos ante un escenario de Política 2.0. en el que se ensamblan la información política y las redes sociales. En él tienen cabida algunos de los principios que destacaba DEL MORAL (2006), inspirándose en el Manifiesto Cluetrain:

- el juego político consiste en enviar información de un punto a una audiencia. Es el modelo de comunicación tradicional, que sigue los principios del telégrafo: un 
emisor envía un mensaje a un receptor con la esperanza de influirle.

- $\quad$ en la Red, se produce una situación inédita: el receptor ignora el mensaje, tiene el control de lo que quiere escuchar y no hará caso salvo que tenga la impresión de que el emisor se dirige a él como individuo.

- Internet promete un sistema de información abierto que permite a todos contrastar la información con otras fuentes.

- utilizando la Red no evitamos a los medios sino que los multiplicamos. Cada internauta se convierte en una posible fuente de opinión.

- más importante que Internet son las comunidades que Internet estructura. En esta realidad radican al mismo tiempo la fuerza y la complejidad del medio.

- la red facilita el acceso a la información y el paso a la acción.

En el diseño de una campaña electoral es importante la coordinación de la campaña digital con la tradicional en medios digitales. "Ello se aprecia no solo en la conformación de equipos de trabajo y organización de departamentos de la campaña digital que trabajan coordinados en su mayoría o integrados en los departamentos de comunicación, sino que también se evidencia en que aquellos mensajes difundidos en Twitter que resultan más viralizados son precisamente los mensajes mediáticos, aquellos que han sido primero difundidos en televisión o los que, aprovechando un evento televisivo consiguen su viralización en Twitter" (CAMPOS DOMÍNGUEZ, CALVO, 2017).

Son muchos autores que abogan porque los políticos deben estar en las redes sociales. Entre ellos, ALCAT (2011): "las personas que quieran influir, además de mantener la relación directa y personal, tendrán que estar, lo quieran o no, en las redes sociales".

Esta presencia hace que los ciudadanos tengan un acceso más sencillo a los líderes. Antes la información política podían obtenerla a través de los diferentes medios de comunicación. Ahora, pueden obtener datos y noticias por ellos mismos con los políticos o sus equipos.

El hecho de que Twitter tenga un claro valor informativo lo ponía de manifiesto Jack Dorsey, su fundador en 2009, cuando señalaba que "no es una red social, sino una herramienta de comunicación" (GUTIÉRREZ-RUBÍ, 2011).

La realidad de las redes sociales crece y, en España, en 2017, su penetración era del $86 \%$, cinco puntos más que el año anterior. El total de usuarios ascendía a 19,2 millones. La red principal era Facebook, con un 91\%. Twitter alcanzaba un nivel de uso del 50\% (IAB SPAIN, 2017).

Facebook, por su parte, se usa para que se comuniquen entre sí aquellos que forman parte de una determinada comunidad, aunque, con frecuencia, se refiere más a mensajes de índole general que de materia política. Esta red tiene una marcada influencia social y demográfica, y sus usuarios acuden ella para obtener necesidades sociales básicas. No obstante, su penetración es relevante especialmente en la población joven dado que suele ser la primera fuente que consultan para obtener información (CAMACHO, KUMAR, 2012). De ahí que los políticos deben tenerla muy presente.

Ambas herramientas son parte de la estrategia de comunicación de un político, pero no son las únicas. Aunque ayudan a diseminar y obtener informaciones deben ir acompañadas de otros recursos y acciones, que pueden tener su base en los medios tradicionales.

\section{OBJETIVOS E HIPÓTESIS}

El principal objetivo de este trabajo consiste en verificar empíricamente si el sistema híbrido de medios de comunicación, de Chadwick, se cumple, especialmente en el caso de Trump. Para ello es necesario, como objetivo secundario, verificar si los tuits publicados por este candidato tienen la repercusión perseguida: lograr el voto.

Se proponen las siguientes hipótesis:

Hipótesis 1: Los líderes políticos investigados (en este caso de Estados Unidos) utilizan las redes para combinar sus propuestas ideológicas con sus informaciones políticas. Las primeras pueden ser para defender sus principios o para rebatir los de los oponentes, y las segundas dan cabida a actos electorales, discursos, vídeos, etc.

Hipótesis 2: Twitter y Facebook son las redes más utilizadas para estos fines. 
Hipótesis 3: Los líderes analizados diseñan estrategias online encaminadas a: (1) mandar informaciones de carácter políticos, (2) convencer a los electores y (3) obtener sus votos.

\section{METODOLOGÍA}

Se han monitorizado los datos que empleó Barack Obama, a través de su propia red social, para valorar su relevancia a la hora de alcanzar la presidencia de Estados Unidos. Un fenómeno en el que se le puede calificar como pionero y que, posteriormente, ha tenido su desarrollo en procesos electorales de diferentes países.

Posteriormente, para analizar la llegada de Donald Trump, se analizan los tuits publicados en su cuenta durante los seis días anteriores a las elecciones de noviembre de 2016, incluido el día de los comicios. La justificación del empleo de este periodo muestral se basa en que son jornadas en las que los candidatos suelen realizar un mayor número de actos de campaña buscando el voto indeciso.

Se estableció un libro de códigos estándar para identificar las variables de análisis:

1. Clases de mensajes

2. Asuntos de los mensajes

3. Frecuencia de los mensajes

La codificación de los resultados fue realizada por un codificador entrenado al efecto y con experiencia en este trabajo de campo. Los términos que más utiliza en sus mensajes así como los tuits con mayor repercusión entre el público fueron también registrados.

\section{ANÁLISIS Y RESULTADOS}

\section{I Obama y la utilidad de las redes}

Uno de los hitos fundamentales que marca la llegada de Barack Obama a la Casa Blanca en 2008 es el uso hecho de las redes sociales. Muy pronto él y su equipo vieron la oportunidad que tenían de hacer llegar mensajes políticos al votante a través de la red y crearon la suya propia, mybarackobama.com.

Durante la campaña de Obama de aquel año, según se recoge en LUTZ (2009):

- 13 millones de personas formaban parte del mailing list

- 5 millones de 'amigos' aparecían en más de 15 redes sociales

- $\quad$ se crearon 35.000 grupos de voluntarios

- se elaboraron casi 2.000 videos en You Tube, que fueron vistos en más de 80 millones ocasiones, con 135.000 suscriptores

- más de 3 millones de personas se suscribieron a un programa de mensajes de móviles. Cada uno recibía de 5 a 20 mensuales

- Y, durante los últimos cuatro días de la campaña, se realizaron 3 millones de llamadas de teléfono personalizadas

Como apunta CASTRO (2012) "todo este despliegue tecnológico colocó la campaña Obama 08 como 'la Política 2.0', misma que explotó y le devino en millones de adeptos y de dólares".

Figura: La política 2.0
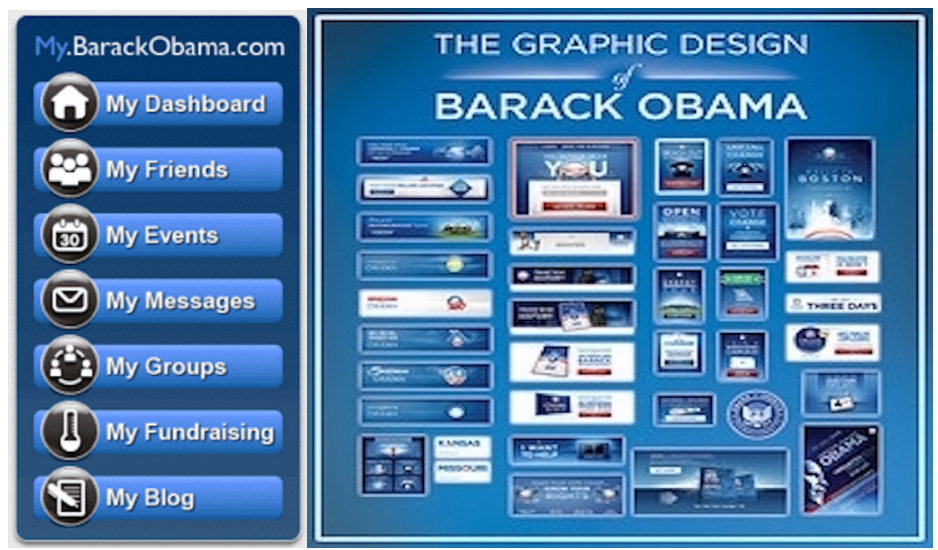

Fuente: Imágenes extraídas de https://comunicacionpoliticaenlared.wordpress.com/tag/barack-obama/.

Inf. \& Soc.:Est., João Pessoa, v.28, n.3, p. 183-191, set./dez. 2018 
A la importancia de Internet se refería Michael Cornfield, experto político y director de investigación del Proyecto Democracia Online de la Universidad George Washington: "sin Internet no habría Obama. La diferencia de comprensión entre las campañas de Obama y Clinton sobre lo que se puede realizar por medio de la política online ha sido un factor decisivo en esa que es el mayor cambio en la historia de las primarias presidenciales. Naturalmente, hay otras diferencias importantes...Pero ninguna de ellas habría sido tan decisiva sin el dinero que Obama recaudó online, los vídeos que Obama publicó online y, además de todo, los millones de personas que adhirieron online a la campaña de Obama, en sus tiempos y términos propios" (GUTERRES, 2009).

En el año en que Obama logra la presidencia de Estados Unidos, 2008, la audiencia de información política a través de la red creció, de ahí que Internet aumentase su relevancia respecto a otras fuentes informativas. Como se ve en la siguiente tabla seis de cada diez usuarios de Internet acudieron a ella para obtener noticias políticas.

Tabla 1: Pew Internet \& American Life Project Surveys

\begin{tabular}{|l|c|c|c|}
\cline { 2 - 4 } \multicolumn{1}{c|}{} & $\mathbf{2 0 0 0}$ & $\mathbf{2 0 0 4}$ & $\mathbf{2 0 0 8}$ \\
\cline { 2 - 4 } \multicolumn{1}{c|}{} & $\mathbf{\%}$ & $\mathbf{\%}$ & $\mathbf{\%}$ \\
\hline $\begin{array}{l}\text { Entre todos } \\
\text { los adultos }\end{array}$ & 18 & 29 & 44 \\
\hline $\begin{array}{l}\text { Entre } \\
\text { usuarios de } \\
\text { Internet }\end{array}$ & 33 & 52 & 60 \\
\hline
\end{tabular}

Fuente: Elaboración propia.

En suma, la estrategia de su campaña sirvió para brindar oportunidades a los partidarios ocasionales y a los activistas más cercanos. De esta forma la campaña de Obama iluminó el camino (DELANY, 2008). Todo el trabajo realizado le sirvió como base para las siguientes elecciones de 2012.

\subsection{La eficacia de Trump en twitter}

Al anunciar su candidatura a las elecciones presidenciales de 2016, Donald Trump sabía que las redes sociales habían significado un hito en los dos mandatos de su predecesor. En ocho años se habían producido avances pero intuía que debía diseñar un plan actualizado que le sirviera para lograr votos y ganar. Algunos de los principios destacados por POSTIGO (2012) se pueden ver en la estrategia de Trump.

1 - Crear una presencia sólida y estable en el tiempo, dándole continuidad. Desde que anunció su candidatura Trump ha mantenido una presencia constante en las redes dirigiéndose a los diferentes públicos.

2 - Aprovechar las ventajas que ofrecen los entornos digitales para incorporar gran cantidad de información, detallada y debidamente clasificada. Muchas de las noticias que él mismo genera las difunde en primer lugar en sus redes.

3 - Lograr una mayor adaptación de los mensajes al electorado objetivo al que se quiere dirigir mediante una adecuada implementación de programas de segmentación. Durante la campaña electoral Trump y su equipo detectaron cuáles eran sus públicos objetivos y a ellos se dirigieron con eficacia aportándoles información vía redes sociales.

4 - Utilizar estrategias que consigan fidelizar a los electores con el fin de lograr mantener relaciones permanentes con ellos para conseguir la máxima eficacia. Además de sus anuncios en televisión y sus mítines en distintos estados, que suponen técnicas más tradicionales, el candidato supo establecer una relación bilateral con el elector a través de los nuevos soportes digitales.

La llegada de Trump a la arena electoral coincidió en el tiempo con la evidencia de que los medios tradicionales y los nuevos soportes tendrían que convivir desde el prisma de la información política. Llevaban ya tiempo haciéndolo y todos los actores ya sabían que no se volvería a tiempos pasados. Esta interacción la recoge Andrew Chadwick en su teoría del 
Sistema de medios híbridos que analiza cómo discurre el poder a través de los medios y cuál es su ascendencia en las campañas electorales, el activismo político o la comunicación gubernamental.

En la $33^{\mathrm{a}}$ edición del Congreso Internacional de Comunicación, celebrada en septiembre de 2017 en la Facultad de Comunicación de la Universidad de Navarra, Chadwick señaló que "el manejo de las redes sociales que realiza Donald Trump no es algo casual, sino que detrás hay una estrategia muy trabajada" (UNAV, 2017).

Como aspectos más relevantes destacó que Trump contrató a Brad Pascale, un estratega en cuestiones digitales que invirtió importantes sumas de dinero en publicidad en Facebook. Incorporó además a su equipo a Steve Bannon, director de Breitbart News, y a la firma Cambridge Analytica. Entre todos identificaron a 13,5 millones de votantes indecisos en estados clave haciéndoles llegar mensajes e informaciones que pudieran lograr el cambio en su intención de voto.

El actual presidente de Estados Unidos utiliza Twitter como herramienta habitual para dar informaciones. Su mala relación con los medios tradicionales ha hecho que la utilicen él y su equipo para dirigirse a los medios y a los ciudadanos. La fuerza de Trump se debe tanto a su prominencia mediática como a su propensión a hacerse viral. Así lo indica PERSILY (2017): "estableció la agenda de noticias. Gracias en parte al hábito de sus seguidores de retuitearlo, sus tuits dominaron el debate de las elecciones en todos los foros".

Dado que esta red es la más utilizada por Trump, en este trabajo se analiza el periodo que comprende los últimos seis días de la campaña electoral de 2016 (desde el 3 de noviembre hasta el 8 de noviembre, día de las elecciones) para comprobar el contenido de los mensajes publicados (en total 52) como la finalidad perseguida por el candidato.

\section{A - Clases de mensajes.}

Pueden destacarse las siguientes:

- Los publicados por Trump. Suelen incluir ataques a sus adversarios del Partido
Demócrata, en especial a Hillary Clinton y Barack Obama. Hace uso de un lenguaje incisivo y crítico (por ejemplo, utiliza los términos 'desastre' o 'máquina de corrupción').

Los de la propia campaña (GARCÍA RIBES, 2017). En este caso emplea las letras mayúsculas. Utiliza con frecuencia el hashtag 'Make America Great Again' y recurre a expresiones de ánimo para fijar a sus seguidores. Anuncia los actos electorales de cada estado y da las gracias después de su celebración. Inserta videos y fotos de estos mítines, e, incluso, en una ocasión hace uso del periscope.

- $\quad$ En ocasiones se refiere a las informaciones o columnas aparecidas en medios como 'The Wall Street Journal', 'The Daily Caller', 'Breitbart', 'Townhall' o 'LifeZette'. En estos casos añade el enlace para que el usuario pueda leerlo en su totalidad.

\section{B - Asunto de los mensajes.}

Aunque en cada uno de ellos suele combinar varios establecemos una lista con los que utiliza con mayor frecuencia.
- Melania: 2
- Hillary: 7
- Obamacare
- Mítines: 27
- Medios: 5
- Make america great again: 4
- Petición de voto: 6

Del total de mensajes publicados en las fechas escogidas, como se indica en el siguiente gráfico, sobresalen las referencias a los mítines (con un 52\%), tanto de su anuncio como del agradecimiento al lugar donde se celebraron. A seguido destacan las referencias a Hillary Clinton, su adversaria en las elecciones, y la petición de voto al ciudadano (con un $13 \%$ y un $11 \%$, respectivamente). Énfasis todos ellos que se explican por la cercanía de las elecciones. 


\section{Gráfico 1: Twitter}

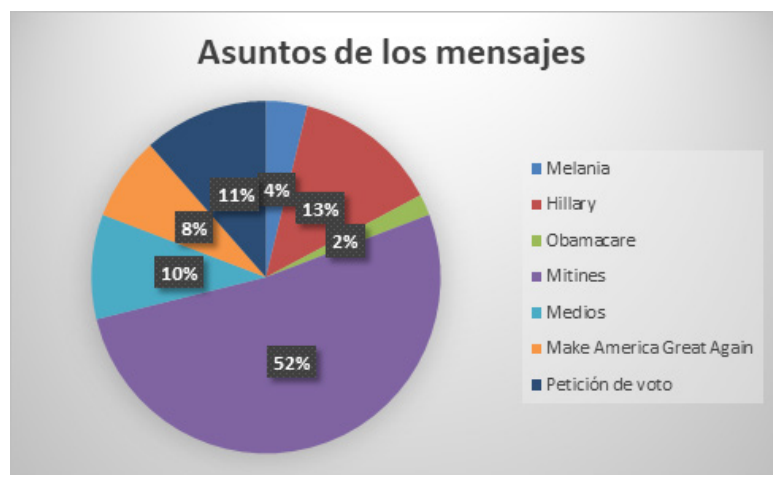

Fuente: Elaboración propia.

\section{C - Frecuencia de los mensajes.}

En el periodo elegido Trump publicó prácticamente el mismo número de tuits al día, excepto el 7 de noviembre. Un hecho que es lógico dado que era la jornada previa a las elecciones y en la que el candidato hizo un mayor esfuerzo por estar en varios estados para enviar sus últimos mensajes a los votantes.

\section{Gráfico 2: Twitter}

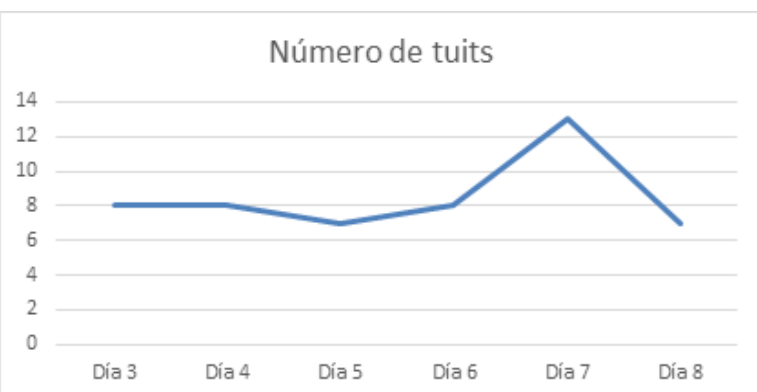

Fuente: Elaboración propia.

En cuanto al dispositivo desde el que Trump escribió los mensajes, un Android o un iPhone, TABACK (2017) realizó un análisis del periodo transcurrido entre el 11 de diciembre de 2012 y el 25 de marzo de 2017 y concluyó que las palabras que aparecen con mayor frecuencia son:

$\begin{array}{ll}\text { - } & \text { People } \\ \text { - } & \text { Hillary } \\ \text { - } & \text { trump2016 }\end{array}$

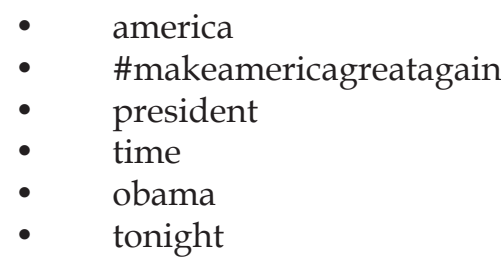

Algunos de los tuits de Trump que han tenido mayor repercusión entre la audiencia son:

1 - El 2 de julio de 2017 difundió un video en el que agredía a la $\mathrm{CNN}$ y la noqueaba en un combate de boxeo. Se trata de un video editado de un evento de lucha libre profesional de Wrestle Mania (GOÑI, 2018), donde ficticiamente Trump se pegaba con otro hombre en "La Batalla de los Millonarios". El distintivo de $\mathrm{CNN}$ aparece sobre la cara del hombre al que abate Trump y termina la frase: "FNN: FraudNewsNetwork". Ha sido reproducido en más de 38 millones de ocasiones y cuenta con más de 350.000 retuits y más de 575.000 'me gusta'.

\section{Imagen 1: Twitter.}
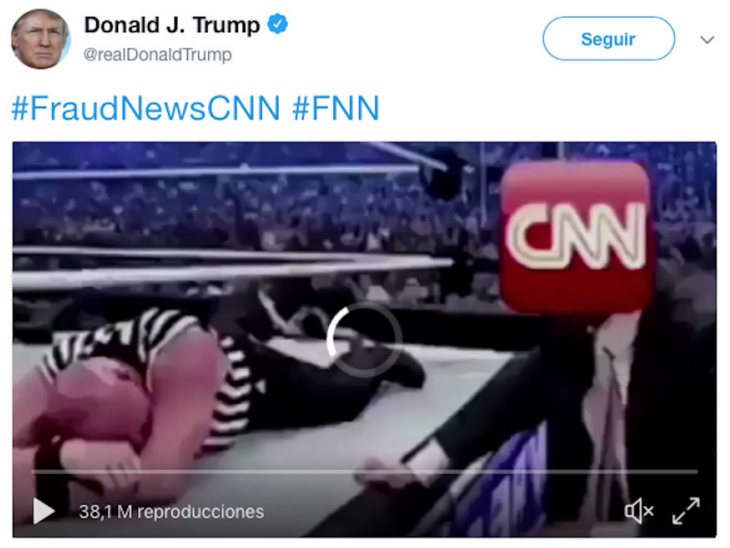

6:21 - 2 jul. 2017

$$
\begin{aligned}
& \text { 349.618 Retweets } 575.757 \text { Me gusta } 968 \\
& Q 137 \mathrm{~K} \quad \mathrm{l}] 350 \mathrm{~K} \quad \bigcirc 576 \mathrm{~K}
\end{aligned}
$$

Fuente: Twitter

2 - El 8 de noviembre de 2016, tras conocer los resultados electorales que le daban como vencedor en las presidenciales, publicó un tuit con el texto "Today we make America great again". Sumó más de 325.000 retuits y más de 550.000 'me gusta'.

3 - El 9 de junio de 2016 Trump hizo una pregunta a Hillary Clinton refiriéndose a 
la investigación sobre el sistema que usó para comunicarse siendo secretaria de Estado durante la administración de Barack Obama. Durante todo el periodo de la campaña este asunto fue muy utilizado por el equipo del candidato republicano con el objetivo de que su rival fuera desgastándose. Obtuvo más 154.000 retuits y más de 278.000 'me gusta'.

4 - El 31 de diciembre de 2016 escribió un tuit en el que felicitaba el nuevo año. Se dirigía a todos los usuarios e incluía también "a mis muchos enemigos y a aquellos que han perdido y no saben qué hacer". Sumó más de 133.000 retuits y 335.000 'me gusta'.

\section{Imagen 2: Twitter}

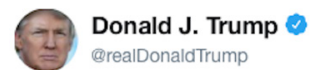

Seguir

Happy New Year to all, including to my many enemies and those who have fought me and lost so badly they just don't know what to do. Love!

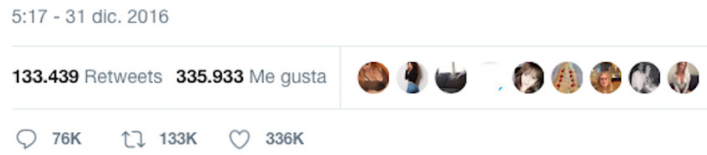

Fuente: Twitter

5 - El 11 de noviembre de 2017 publicó un mensaje en el que llamaba "gordo bajito" al líder norcoreano Kim Jong Un. Se refería a unas declaraciones en las que éste le habría llamado "viejo". Trump señalaba también en su tuit que estaba haciendo todo lo posible para ser su amigo. Obtuvo más de 263.000 retuits y más de 609.000 'me gusta'.

El hashtag @realDonaldTrump genera incertidumbre porque Donald Trump es el primer presidente estadounidense que se expone con el público de manera personal, tal y como indican SÁNCHEZ-GIMÉNEZ Y TCHUBYKALO (2018): "anulando los modelos tradicionales de comunicación política en términos de la formalidad del lenguaje y el uso frecuente del sentimiento negativo".

\section{CONCLUSIONES}

Esta investigación ha permitido confirmar empíricamente que asistimos a un robustecimiento de las redes sociales como una herramienta útil para la información política. Su relevancia hace que sean uno de los principales vehículos para que los líderes puedan enviar sus mensajes políticos a los potenciales electores.

En segundo lugar, se confirma que son Twitter y Facebook las redes más utilizadas dada su alta penetración entre los diferentes públicos.

En tercer lugar, los datos parecen demostrar que Barack Obama diseñó una estrategia online, que resultó ser pionera: a través de su propia plataforma logró que sus mensajes e informaciones llegaran al electorado de forma eficaz. Se convirtió en una de las claves para que alcanzara la presidencia en 2008 y la base para que revalidara sus resultados en 2012.

Y, en cuarto lugar, la comparación de resultados entre ambos políticos, permiten inferir que el camino recorrido por Obama lo continúa Donald Trump. Desde el primer momento, diseñó una estrategia de comunicación en la cual las redes serían su aliado dada su enemistad con la gran mayoría de los medios tradicionales. Los resultados indican que la eficacia de la campaña en redes puede deberse, en gran medida, al análisis realizado de su target electoral al cual se dirigió con eficacia.

Nuestros datos indican que Trump es el presidente que envía informaciones de forma directa y sin intermediarios de forma eficaz. Futuras investigaciones (con futuros presidentes) confirmarán si esta estrategia obedece más a la personalidad del presidente o a una tendencia emergente en este campo de la comunicación política. 
Artigo recebido em 08/I I/20। 8 e aceito para publicação em 08/I2/20। 8

\title{
POLITICAL INFORMATION AND SOCIAL NETWORKS IN THE UNITED STATES: from Obama to Trump
}

\begin{abstract}
In the field of political information, we witness a media hybridization that explains the new consumption of news. In recent years, the most relevant leader in making political / electoral use of social networks was Barack Obama. He designed an online strategy that, among other factors, added to the presidency of the United States. In 2016, Donald Trump detected the target to be addressed, listened to them and established an online campaign to send them messages of political information. The purpose of this article is to analyze and monitor the Obama and Trump networks, during the critical electoral period with the ultimate goal of collaborating with the new models of political communication to verify if the results, as noted by CHADWICK (2013), confirm that the new media are interrelated with the old ones.
\end{abstract}

Keywords: $\quad$ USA. Communication. Elections. Information media.

\section{REFERENCIAS}

ALCAT, E. ¡Influye!: claves para dominar el arte de la persuasión. Barcelona: Alienta, 2011.

CAMACHO, R,. KUMAR, M. Social Media on e- Government. 2012. Disponible: <https:// diuf.unifr.ch/main/is/sites/diuf.unifr.ch.main. is/files/documents/student-projects/Group5 Camacho_Kumar.pdf> Acceso en: 12 jun. 2018

CAMPOS DOMÍNGUEZ, E., CALVO, D. La campaña electoral en Internet: planificación, repercusión y viralización en Twitter durante las elecciones españolas de 2015. Comunicación y Sociedad, n. 29, pp. 93-116, 2017.

CASTRO, L. El marketing político en Estados Unidos: el caso Obama. Norteamérica, v. 7, n. 1, 2012.

CHADWICK, A. The Hybrid Media System. Politics and Power. Nueva York: Oxford University Pres,. 2013.

DELANY, C. Inside the Obama Numbers: Tiers of Engagement. Techpresident. Disponible: <http://techpresident.com/news/6578/insideobama-numbers-tiers-engagement $>$. Acceso en: 12 jun. 2018

DEL MORAL, J. A. Los principios de la política 2.0. 2006. Disponible: <http://blogs.alianzo. com/redessociales/2006/02/21/los-principiosde-la-politica-2-0/>. Acceso en: 11 jun. 2018

GARCÍA RIBES, M. M. El uso de las redes sociales en política: el caso de Donald Trump. (Trabajo Fin de Grado) - Universitat Politécnica de Valencia, 2017.

GOÑI, A. Comunicación política y nuevas tecnologías. Trump y su estrategia en Twitter. (Trabajo Fin de Grado) - Universidad Complutense de Madrid, 2018.

GUTERRES, F. A. La campaña online de Barack Obama en 2008, Cuadernos de H Ideas, v. 3, n. 3, 2009. Disponible: <http://perio.unlp.edu.ar/ojs/ index.php/cps/article/view/1391/1968>. Acceso em: 11 jun. 20018.

GUTIÉRREZ-RUBÍ, A. Twitter, mucho más que la CNN. El Periódico de Catalunya. Disponible: <https://www.elperiodico.com/es/ opinion/20110704/twitter-mucho-mas-que-lacnn-1064457>. Acceso en: 11 jun. 2018

IAB SPAIN. Estudio anual redes sociales. Disponible: <https://iabspain.es/wp-content/ uploads/iab_estudioredessociales_2017_ vreducida.pdf>. Acceso en: 12 jun. 2018

LUTZ, M. The Social Pulpit: Barack Obama's Social Media Toolkit. 2017. Disponible: <http:// 
cyber.law.harvard.edu/sites/cyber.law.harvard. edu/files/Social\%20Pulpit\%20- \%20Barack\%20 Obamas\%20Social\%20Media\%20Toolkit\%201.09.pdf >. Accesso en: 14 jun. 2018.

PERSILY, N. The 2016 US Election. Can Democracy Survive the internet?. Journal of Democracy, v. 28, n 2, pp. 63-76. 2018. Disponible: <https://www.journalofdemocracy.org/sites / default/files/07_28.2_Persily\% 20\%28web\% 29. pdf>. Acceso em: 18 jun. 2018

POSTIGO, M. A. L. Campaña en la Red. Estrategias de marketing electoral en Internet. Redmarka, Revista Académica de Marketing Aplicado, año X, número 19, V1, pp.177-199, 2012. Disponible: <http://cienciared.com.ar/ $\mathrm{ra} /$ revista.php? wid $=39 \&$ articulo $=1660 \&$ tipo $=$ $\mathrm{A} \& \mathrm{~s}$ i d $=195 \& \mathrm{~N}$ o $\mathrm{m}$ b r e Seccion=Articulos\&Accion=Ver $>$. Accesso :14 jun. 2018.

SÁNCHEZ-GIMÉNEZ, J. A., TCHUBYKALO, E. Donald Trump's Twitter account: a brief content analysis. Analyses of the Elcano Royal Institute, 2018. Disponible: <http://www. realinstitutoelcano.org/wps/portal/rielcano_ en/contenido?WCM_GLOBAL_CONTEXT=/ elcano/elcano_in/zonas_in/ari20-2018sanchezgimenez-tchubykalo-realdonaldtrump-abrief-content-analysis>. Acceso em: 18 jun. 2018.
SMITH, A. The Internet's role in campaign 2008. Pew Research Center. Disponible: <http:// www.pewinternet.org/2009/04/15/theinternets-role-in-campaign-2008/>. Acceso em: 12 jun. 2018.

TABACK, N. Data Analysis of Trump Tweets. Utstat.toronto.edu, 2017. Disponible: <http:// utstat.toronto.edu/ nathan/teaching/sta4002/ Class4/trumptweets-sampleproject1.html>. Acceso en: 12 jun. 2018.

UNAV. El manejo de las redes sociales de Trump no es casual, es una estrategia muy trabajada,2017. Disponible: <http:// www.unav.edu / web / alumni / noticiapestana/2017/09/08/"el-manejo-de-las-redessociales-de-trump-no-es-casual-es-una-estrategiamuy-trabajada" articleId=15540930 > . Accesso en: 14 jun. 2018.

VONDERSCHMITT, K. The Growing Use of Social Media in Political Campaigns: How to use Facebook, Twitter and YouTube to Create an Effective Social Media Campaign. Honors College Capstone Experience/Thesis Projects. Paper 360, 2017. Disponible: <http://digitalcommons.wku. edu/stu_hon_theses/360 >. Acceso en: 12 jun. 2018. 
